\title{
Are Names Really Empty: A Look into Shona Dog Names
}

\author{
Dr. Isaac Mhute \\ Zimbabwe Open University, Masvingo
}

doi: 10.19044/esj.2016.v12n11p312 URL:http://dx.doi.org/10.19044/esj.2016.v12n11p312

\begin{abstract}
Following the popular Shakespearean saying that there is nothing in a name, the paper ventures into the linguistic area of onomastics focusing on uncovering the exact truth behind names in societies. It takes the Shona people's dog names as a case study and reports on results from a qualitative research that used observations and open ended interviews as data collection techniques. Purposive sampling was employed and saw most of the data coming from districts in Masvingo province such as Zaka, Masvingo and Ndanga. Data were either recorded using a Samsung phone or recorded in the researcher's notebook before being qualitatively analysed and interpreted. It came out that, though in certain situations names are just tags meant to enhance identification of certain dogs just like the Biblical names that were given to most African children following the coming of the former white masters, almost every Shona dog name has a story behind it.
\end{abstract}

Keyterms: Onomastics, Shona dog names

\section{Introduction and Orientation}

Shakespeare's popular saying that there is nothing in a name, that seem to encourage people not to care much about what names are given, has attracted a lot of attention over the years with many making efforts to follow it up from biblical terms among others. One good example is Ronnie McCarty who makes frantic efforts to dismiss the claim in the Truth Magazine XXII of April 13, 1978 as presented on http://www.truthmagazine.com/archives/volume22/TM022136.html. He analyses names of biblical characters like Moses, Zacharias, Jesus and Christ demonstrating how loaded they are with meaning. McKie (2013) argues that throughout the twentieth century, a taste for these interests developed until the pursuit of surnames, and of family histories generally, became a craze, an addiction, even in a sense a religion, with its own high priests, that is, the species of academics now known as onomasticians. 
This paper falls under this broad linguistic area of onomastics. According to http://grammar.about.com/od/mo/g/onomasticsterm.htm, onomastics is the study of the origin, history, and use of proper names. Onomastics originates from the Greek ovo $\mu \alpha \sigma \tau$ เós (onomastikos), which

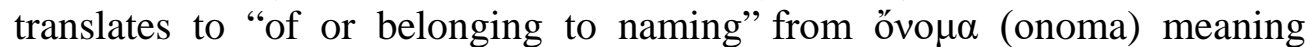
"name". It is a field that is well known for data mining especially in the areas like language and gender. Various observations have been made over the years on the area in question. For instance, Algeo (1992) notes that onomastics has popular branches, that is, the study of place-names (toponymy) which is closely allied to geography, history, and related disciplines. There is also the study of personal names (anthroponymy) which is relates and benefits genealogy, sociology, and anthropology. He further observes that there is another new sub-discipline named literary onomastics, which examines the use of proper names in literature, and often focuses on the names of characters in fiction (characternyms).

Coates (1999) has it that, as a result of the studies, various striking features of American names have been uncovered, for instance, in placenaming there is the frequency of incident-names, some of very banal origin. He observes that "Massacre Rocks (ID) commemorates the killing of emigrants there in 1862; Hatchet Lake (AK) was so-called because a surveyor cut his knee on a hatchet there in 1954; Peanut (CA) was named by the postmaster, who, when asked for his views on a possible name, happened to be eating his favorite peanuts at the time; at Kettle Creek kettles were lost; and at Man-Eater Canyon (WY) a reputed murderer and cannibal was finally arrested".

This paper looks into yet another sub-branch in onomastics, that is, of dog names. It focuses on finding out the secret behind the dog names in the Shona society. According to Guthrie (1948), Shona (or ChiShona) is a Bantu language, native to the Shona people of Zimbabwe and southern Zambia. The term is also used to identify peoples who speak one of the Shona language dialects, namely Zezuru, Karanga, Manyika, Ndau and Korekore. It is a principal language of Zimbabwe, along with Ndebele and the official business language, English. Shona is spoken by a percentage of about 75\% of the people in Zimbabwe. Mutasa (1996) notes that according to ethnologue, the five major dialects of Shona are natively spoken by 13.8 million people making it one of the largest Bantu languages. Other countries that host Shona language speakers are Zambia, Botswana and Mozambique. Shona is a written standard language with an orthography and grammar that was codified during the early 20th century and fixed in the 1950s. Shona is taught in the schools but is not the general medium of instruction in other subjects. It has literature and is described through monolingual and bilingual dictionaries (chiefly Shona - English). Mutasa (1996) notes that modern 
Shona is based on the dialect spoken by the Karanga people of Masvingo Province, the region around Great Zimbabwe as well as Zezuru spoken by people of central and northern Zimbabwe. It is a member of the great family of Bantu languages. In Guthrie's (1948) zonal classification of Bantu languages, zone S10 designates a dialect continuum of closely related varieties.

\section{Statement of the Problem}

The popular Shakespearean assertion that 'there is nothing in a name' seems to have made a mark in the world by having many subscribe to it as well as triggering endless debates related to humans and place names. This paper is taking the debate further by venturing into this linguistic field of onomastics to focus on uncovering the truth behind Shona dog names.

\section{Significance}

Efforts to interrogate Shakespeare's assertion have delved mainly into human and place names leaving out many areas. This paper delves into one of the seemingly neglected areas. It is likely to raise awareness on how certain situations were handled by the Shona since onomastics has since emerged as one of the main data mining avenues (McKie, 2013).

\section{Research Questions}

- $\quad$ Are Shona dog names really empty?

- If not, what do they really carry?

- Why did the Shona have to house such information in dog names?

- $\quad$ How effective was the method?

\section{Research Objectives}

- $\quad$ To assess if there is really nothing in Shona dog names

- If not, to find out the nature of the housed information

- $\quad$ To establish the reason the Shona used dog names for the purpose

- $\quad$ To examine the effectiveness of the method

\section{Research Methodology}

This research adopted the qualitative paradigm and a case study design. It took the Shona people as the population and went on to purposively sample out Zaka, Masvingo and Ndanga districts as sources of data collected using observation and open-ended interviews. Data were analysed qualitatively. 


\section{Findings}

This study established that Shona dog names carry various messages. Three types of names have been discovered in the process:

\section{Names denoting physical features}

The informants indicated that they sometimes give their dogs names that are meant to act as tags for the identification of the dogs. They could refer to the colour of the dog e.g. 'white', how it behaves or cope to nature e.g. 'mukurandoda' (growing when I want) for a dog whose pace of growing is too slow or artificial features put on them like 'Bhingo' (bangle) for a small dog whose owner has tied a small belt around its neck for easy handling when taking morning walks. One may not call such names empty as they say something about the behaviour or physical attributes of the dog.

\section{Names highlighting what they expected of the dogs}

It came out as well that there are cases when dogs would be given names emphasising some of the attributes they would want them to have when they grow up. This follows the Shona people's belief that the name one gives an animal or person inspires it as it grows. For instance, one hunter who wanted the dog to be a fast runner named his dog 'spider'. Lion and shumba are other common dog names they said were usually given to make dogs very brave. Bravery to them was said to be quite necessary as dogs are meant to guard homes from thieves and wild animals like Hippos, baboons, leopards among others. One informant indicated that apart from saying out your expectations to a newly born dog, one would at times come to realise some features in a grown up dog and decide to celebrate them by changing its name accordingly.

\section{names commenting on relatives and enemies' behaviours}

It also came out that, though tensions usually emerge especially between daughter-in-laws, mother-in-laws, sister-in-laws and neighbors, the Shona people value relationships at all costs. They say the people around you are your most valuable form of insurance. However, this does not prevent them from criticizing or commenting on bad practices though this is done in ways that guarantee preservation of the much valued relationships. One most subscribed to way of doing that was through passing their criticisms in the form of dog names. This led to a whole lot of derogatory names examples of which are listed below together with reasons dog owners chose them.

- $\quad$ Zvichapera (it will end) - a lesson to a pompous wealthy neighbour meant to urge him to view and treat the poor as humans. A similar name from another district is 'mugaromwena'.

- Vanhukwaidza (only humans during the day) - a message to surrounding witches people that we know that during the night you change 
into monsters and become humans during the day. This would make them change their unacceptable behaviour. Names with similar meanings but from other districts are 'hakurarwi' (there is no sleep), 'taitivanhu' (thought they are humans) and 'kurarofamba' (walking all night). The latter is also related to 'kwaedzerofamba' (day time comes for walking) a name in a different village attacking the family daughter-in-law's habit of moving around every day.

- $\quad$ Nenga (idiophone for something placed at the top most position) meant to criticise a neighbour who always want to place himself right on top of everyone as if he is the only one around even where it is not necessary.

- Guhwa (rumor) - husband advising wife to always shun gossip no matter its level or flavor.

- $\quad$ Bastard - English name meant to insult a neighbour believed to be killing the family's children.

- $\quad$ Kumukakwindi (sitting once out of bed) - message to a lazy daughterin-law to stop the bad practice. This practice also bred other bad names in a nearby village like 'kwenyu hakuna vakuru' (there are no elders at your place). This means there are no people who could advice you on the good practices that are typical of a daughter-in-law.

- $\quad$ Takambofara (we once enjoyed) - a message intended for a wife who is now neglecting the husband because they have finished all the money that attracted her to him.

- $\quad$ Kurerashumba (bringing up a lion) - message to a child who has been brought up so well only to turn into a monster.

- $\quad$ Muroyindishe (a witch is a king) - comment on how powerful and peaceful a witch becomes at the expense of other people's happiness.

- Muchoni (someone who once went away for quite a long period) wife reminding the husband that he once left them for South Africa for years only to return empty handed. She said this was her way of calling for the respect she deserves as she single-handedly kept the family intact on his behalf.

All these examples indicate that, in actual fact, Shona dog names are far from being empty. They have lots of stories they tell. Asked on why they chose a dog for sending such sensitive messages, informants said a dog has the ability to be referred to using a class 5 noun prefix -ri- which makes most harsh words applicable to it. It is also an animal that humans do not so respect making it a perfect candidate for the task. They indicated as well that dogs are usually around when you would want to deliver your message. They live with people and their usual restless behaviour would provide enough chances for their names to be called at any time and in most cases accompanied by all sorts of harsh words and beatings. They indicated that 
once they do that they would feel as if a beat down would have been delivered to the targeted person not the dog.

Asked on whether this was effective, the informants indicated that this is the most effective way of sending such messages since time immemorial. One old man indicated that in most cases you would see the person quickly shifting from the behaviour. However, another informant argued that the effectiveness is more on the side of his heart. Saying what you were being denied an opportunity to say to your enemy by the cultural norms and values provides the most relief one would wish for. He regards that opportunity as the reason he is leading a stress free life despite the lots of troubles characterising his life. This demonstrates how central the messages encoded in dog names are to decent societies like that of the Shona people.

\section{Conclusion}

The research demonstrated that names are indeed loaded with messages of varying types. The Shona make them a platform for them to deliver reminders, lessons, criticisms, descriptions, expectations as well as messages that their culture regard as unfit for their neighbors, relatives or enemies. They regard the opportunity as the one ensuring stress free lives even in cases where the family would have been hit by countless deaths in a short while.

\section{References:}

Algeo, J. 1992. “Onomastics.” In Tom McArthur (ed.) The Oxford Companion to the English Language, New York: Oxford University Press.

Coates, R. 1999. “Onomastics,” In Richard M. Hogg et al. The Cambridge History of the English Language, Volume IV.

Guthrie, M. 1948. The Classification of the Bantu languages. London: Oxford University Press for the International African Institute.

McKie, D. 2013. "What's in a Surname?” A Journey from Abercrombie to Zwicker. Random House.

Mutasa, D. 1996. The problems of standardizing spoken dialects: the Shona experience, Language Matters, 27, 79.

http://grammar.about.com/od/mo/g/onomasticsterm.htm Accessed on 15 March 2016

http://www.truthmagazine.com/archives/volume22/TM022136.html

Accessed on 16 March 2016 